\title{
Effect of the working liquid compressibility on the picture of volumetric and mechanical losses in a high pressure displacement pump used in a hydrostatic drive
}

\author{
Part I
}

\author{
Energy losses in a drive system, \\ volumetric losses in a pump
}

Zygmunt Paszota, Prof.

Gdansk University of Technology, POLAND

\section{ABSTRACT}

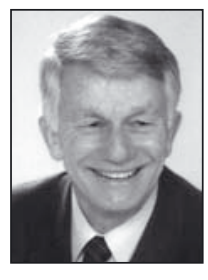

Working liquid compressibility may considerably change the values and proportions of coefficients of volumetric and mechanical energy losses in the displacement pump used in a hydrostatic drive system. This effect can be particularly seen in the operation under high pressure and also in the system, where aeration of the working liquid can occur. In the Part I a diagram is presented, proposed by the author, of power increase in a hydrostatic drive system (hydraulic motor, pump) opposite to the direction of power flow, replacing the Sankey diagram of power decrease in the direction of power flow. Mathematical model is presented of volumetric losses in the pump and its laboratory verification.

Keywords: hydrostatic drive system; pressure displacement pump; energy losses; energy efficiency; energy saving; liquid compressibility; Sankey diagram;

\section{INTRODUCTION}

The evaluation of energy efficiency of hydrostatic drive system elements (pump, hydraulic motor, throttling control assembly, conduits) is only justified when performed during their operation in the system. The hydraulic motor speed control structure determines in an essential way the level of power of energy losses in the system elements, losses related to the instantaneous values of the hydraulic motor speed $\bar{\omega}_{M}$ and load $\overline{\mathrm{M}}_{\mathrm{M}}$ coefficients as well as to the working liquid viscosity ratio $v / v_{\mathrm{n}}[1 \div 19]$.

Evaluation of the energy efficiency of a displacement machine (pump, hydraulic motor), performed independently of the drive system cannot be used for evaluation of energy efficiency of the system where the machine is operating.

It is necessary to evaluate the energy (mechanical, volumetric and pressure) losses in the pump and hydraulic motor as a function of the machine parameters which directly effect the losses. It is also necessary to determine the $k_{i}$ coefficients of those losses. The knowledge of $k_{i}$ coefficients allows to develop the mathematical models of losses taking into account also the system structure. The mathematical models should also allow to evaluate losses and energy efficiency of the elements and the system as a whole as a function of the hydraulic motor speed $\bar{\omega}_{M}$ and load $\overline{\mathbf{M}}_{\mathrm{M}}$ coefficients as well as a function of the working liquid viscosity ratio $v / v_{n}$.
The knowledge of $\mathrm{k}_{\mathrm{i}}$ coefficients of losses in the elements allows also to determine the necessary mathematical models describing the maximum values $\bar{\omega}_{M \max }=\mathrm{f}\left(\overline{\mathrm{M}}_{\mathrm{M}}\right)$ and $\overline{\mathrm{M}}_{\mathrm{Mmax}}=\mathrm{f}\left(\bar{\omega}_{\mathrm{M}}\right)$ of the hydraulic motor operating field $\left(0 \leq \bar{\omega}_{\mathrm{M}}\left\langle\hat{\omega}_{\mathrm{M} \text { max }}, 0 \leq \overline{\mathrm{M}}_{\mathrm{M}}\left\langle\overline{\mathrm{M}}_{\mathrm{M} \max }\right)\right.\right.$ in a system with a given structure, the field that changes also with the change of the working liquid viscosity ratio $v / v_{n}$.

Compressibility of the working liquid (hydraulic oil) in the working chambers of the investigated pump decreases the volumetric intensity $Q_{P}$ of flow in the discharge conduit compared with the intensity of low pressure flow in the pump inlet conduit. Therefore it reduces the theoretical volume $q_{P t}\left(V_{P}\right)$ and the geometrical volume $q_{\text {Pgv }}\left(V_{\text {Pgv }}\right)$ of the pump operating under high pressure. The liquid compressibility increases at the same time the value of coefficient $k 1$ of the volumetric losses in the pump.

Simultaneously, the liquid compressibility, reducing the theoretical volume $q_{P t}\left(V_{P}\right)$ and the geometrical volume $q_{P g v}$ $\left(V_{\text {Pgv }}\right)$ of the pump working chambers, decreases the value, determined in the investigation, of the coefficient $k_{4.2}$ of the increase $\Delta M_{\mathrm{Pm} / \mathrm{AP} \text {, }}, b_{\mathrm{P}}, v_{\mathrm{n}}$ of torque of mechanical losses in the ,working chambers - shaft" assembly. The increase of torque is a function of the torque MPi indicated in the working chambers.

The coefficient $\mathrm{k}_{\mathrm{lc} \mid \mathrm{p}_{\mathrm{n}}}$ of working liquid compressibility has been introduced in the analysis. 
The $\mathrm{k}_{\mathrm{lc|} \mathrm{p}_{\mathrm{n}}}$ coefficient is defined at the increase $\Delta \mathrm{p}_{\mathrm{Pi}}$ of pressure in the pump working chambers equal to the system nominal pressure $\mathrm{p}_{\mathrm{n}}-\Delta \mathrm{p}_{\mathrm{Pi}}=\mathrm{p}_{\mathrm{n}}$.

The working liquid compressibility coefficient $\mathrm{k}_{\mathrm{lc|} \mathrm{p}_{\mathrm{n}}}$ determines the degree of decrease, as an effect of compressibility (without taking leakage into account), of the active volume of the working liquid displaced by the pump in one shaft revolution, compared with the active volume equal to the theoretical capacity $\mathrm{q}_{\mathrm{Pt}}\left(\mathrm{V}_{\mathrm{Pt}}\right)$ or geometrical capacity $\mathrm{q}_{\mathrm{Pgv}}\left(\mathrm{V}_{\mathrm{Pgv}}\right)$ per one shaft revolution determined at the increase $\Delta \mathrm{p}_{\mathrm{Pi}}$ of pressure in the working chambers equal to zero $-\Delta \mathrm{p}_{\mathrm{Pi}}=0$ :

$$
\begin{gathered}
\mathrm{k}_{\mathrm{lc} \mid \mathrm{p}_{\mathrm{n}}}=\frac{\mathrm{q}_{\mathrm{Pt}}-\mathrm{q}_{\mathrm{Pt} \mid \Delta \mathrm{p}_{\mathrm{Pi}}=\mathrm{p}_{\mathrm{n}}}}{\mathrm{q}_{\mathrm{Pt}}} \\
\mathrm{k}_{\mathrm{lc} \mid \mathrm{p}_{\mathrm{n}}}=\frac{\mathrm{q}_{\mathrm{Pgv}}-\mathrm{q}_{\mathrm{Pgv} \mid \Delta \mathrm{p}_{\mathrm{Pi}}=\mathrm{p}_{\mathrm{n}}}}{\mathrm{q}_{\mathrm{Pgv}}}=\frac{\mathrm{b}_{\mathrm{P}} \mathrm{q}_{\mathrm{Pt}}-\mathrm{b}_{\mathrm{P}} \mathrm{q}_{\mathrm{Pt} \mid \Delta \mathrm{p}_{\mathrm{Pi}}=\mathrm{p}_{\mathrm{n}}}}{\mathrm{b}_{\mathrm{P}} \mathrm{q}_{\mathrm{Pt}}}
\end{gathered}
$$

It is possible to evaluate the effect of coefficient $\mathrm{k}_{\mathrm{lc|} \mathrm{p}_{\mathrm{n}}}$ of liquid compressibility on the value of the coefficient $\mathrm{k}_{4.2}$ of the increase of torque of mechanical losses in the pump ,working chambers - shaft" assembly and then to evaluate the effect of that coefficient on the value of coefficient $k_{1}$ of volumetric losses in the pump working chambers. This is possible during investigation of the pump with variable capacity $q_{P g v}\left(b_{P} q_{P t}\right)$ per one shaft revolution.

The working liquid compressibility has no effect on the evaluation of coefficient $\mathrm{k}_{8}$ of volumetric losses in the working chambers of the hydraulic rotational motor and also on the evaluation of coefficient $\mathrm{k}_{72}$ of the increase of torque of mechanical losses in the motor "shaft - working chambers" assembly.

The hydraulic motor working chambers are fed with compressed working liquid (with the pressure resulting, among others, from the torque $\mathrm{M}_{\mathrm{M}}$ on the motor shaft). The calculated value of the torque $\mathrm{M}_{\mathrm{Mi}}$ indicated in the motor working chambers is not influenced by the change of the theoretical volume $\mathrm{q}_{\mathrm{Mt}}\left(\mathrm{V}_{\mathrm{M}}\right)$ or geometrical volume $\mathrm{q}_{\mathrm{Mgv}}\left(\mathrm{V}_{\mathrm{Mgv}}\right)$ of the motor working chambers.

\section{DIRECTION OF POWER INCREASE IN THE DRIVE SYSTEM}

The Sankey diagram is the fundamental cause of incorrect evaluation of losses in a drive system.

The Sankey diagram connected with a drive system suggests an evaluation defining the output power of the system as a difference between the system input power and sum of the powers of losses occurring in the system. Therefore the energy losses in the system are evaluated as a function of parameters describing the input power.

In accordance with the proposed by the author (Fig. 2.1) diagram of power increase in a power transmission system opposite to the direction of power flow, the system input power is a sum of the system output power and powers of losses occurring in the system. The energy losses in the system are evaluated as a function of parameters describing the system output power.

Full picture of the energy losses in a hydrostatic drive system is a picture of power of energy losses in the system elements. Shaft power of the system feeding pump is equal to the sum of hydraulic motor shaft (or piston rod) power and powers of individual losses in the power flowing from the pump shaft to the hydraulic motor shaft (or piston rod).

The quantity of power increases, in order to overcome the power of energy losses, in the opposite direction to the direction of power flow. Therefore, the image of power of energy losses in the system should be constructed in the direction from the hydraulic rotational motor shaft or from linear motor piston rod towards the system feeding pump shaft.

Power of the hydraulic motor, pump and other system element losses (mechanical, volumetric, pressure losses) should be determined as functions of the parameters independent of those losses and influencing directly those losses.

Power of energy losses in the system elements and also power of those elements must be precisely defined.

Fig. 2.1 presents (as an example of the system with the hydraulic motor speed series throttling control assembly fed by a constant capacity pump cooperating with an overflow valve) the diagram, proposed by the author, of the direction of power increase from the shaft or piston rod of a hydraulic motor to the pump shaft, power increasing as an effect of the imposed powers of energy losses in the hydrostatic drive and control elements.

The useful power $\mathrm{P}_{\mathrm{Mu}}=\mathrm{M}_{\mathrm{M}} \omega_{\mathrm{M}}$ determined on the rotational hydraulic motor shaft or $\mathrm{P}_{\mathrm{Mu}}=\mathrm{F}_{\mathrm{M}} \mathrm{v}_{\mathrm{M}}$ determined on the linear hydraulic motor piston rod, changing in the work field $\left(0 \leq \mathrm{M}_{\mathrm{M}}\right.$ $<\mathrm{M}_{\mathrm{M} \max }$ and $\left.0 \leq \omega_{\mathrm{M}}<\omega_{\mathrm{M} \max }\right)$ or $\left(0 \leq \mathrm{F}_{\mathrm{M}}<\mathrm{F}_{\mathrm{M} \max }\right.$ and $0 \leq \mathrm{v}_{\mathrm{M}}<$ $\mathrm{V}_{\mathrm{Mmax}}$ ) of the motor driven device, is a result of instantaneous requirements of the device toward motor both as regards load $\mathrm{M}_{\mathrm{M}}\left(\mathrm{F}_{\mathrm{M}}\right)$ and speed $\omega_{\mathrm{M}}\left(\mathrm{v}_{\mathrm{M}}\right)$. Therefore, the instantaneous useful power $\mathrm{P}_{\mathrm{Mu}}$ is independent of the structure of hydraulic system (used for changing the motor speed $\omega_{M}\left(v_{M}\right)$ ) and of the power $\Delta P$ of losses in the system elements. However, this does not apply to the upper limits of the device parameter ranges, i.e. maximum load $\mathrm{M}_{\mathrm{M} \max }\left(\mathrm{F}_{\mathrm{M} \max }\right)$ and maximum speed $\omega_{\mathrm{M} \max }\left(\mathrm{v}_{\mathrm{M} \max }\right)$.

The upper limits of work field, determined by the $\mathrm{M}_{\mathrm{M} \max }=$ $=\mathrm{f}\left(\omega_{\mathrm{M}}\right)$ and $\omega_{M \max }=\mathrm{f}\left(\mathrm{M}_{\mathrm{M}}\right)$ or $\mathrm{F}_{\mathrm{M} \max }=\mathrm{f}\left(\mathrm{v}_{\mathrm{M}}\right)$ and $\mathrm{v}_{\mathrm{M} \max }=\mathrm{f}\left(\mathrm{F}_{\mathrm{M}}\right)$ lines, of the hydraulic motor driving the device, depend on the theoretical capacity $\mathrm{Q}_{\mathrm{Pt}}$ of the pump in the system, on the nominal pressure $p_{n}$ level of the system operation (the product $\mathrm{Q}_{\mathrm{Pt}} \mathrm{p}_{\mathrm{n}}$ is the reference power), on the motor speed control structure used, and also on the sum $\Delta \mathrm{P}$ of powers of losses in the system elements. The upper limits of the motor work field differ in systems with different motor speed control structures.

On the other hand, the instantaneous power $\mathrm{P}_{\mathrm{P}_{\mathrm{c}}}=\mathrm{M}_{\mathrm{P}} \omega_{\mathrm{P}}$ required (consumed) by the pump from the drive (electric or internal combustion) motor, determined on the pump shaft, is a sum of the instantaneous useful power $\mathrm{P}_{\mathrm{Mu}}$ of the hydraulic motor and instantaneous sum $\Delta \mathrm{P}$ of powers of losses in the hydraulic system elements:

$$
\mathrm{P}_{\mathrm{Pc}}=\mathrm{P}_{\mathrm{Mu}}+\Delta \mathrm{P}
$$

Power $\mathrm{P}_{\mathrm{Pc}}$ on the pump shaft is equal to the sum $\Delta \mathrm{P}$ of power of energy losses in the system elements $\left(\mathrm{P}_{\mathrm{Pc}_{\mathrm{c}}}=\Delta \mathrm{P}\right)$ during operation with the unloaded motor (when $\mathrm{M}_{\mathrm{M}}=0$ or $\mathrm{F}_{\mathrm{M}}=0$ ) or with the stopped motor (when $\omega_{\mathrm{M}}=0$ or $\mathrm{v}_{\mathrm{M}}=0$ ). The useful power $\mathrm{P}_{\mathrm{Mu}}$ of the motor and energy efficiency $\eta$ of the system are then equal to zero $\left(\mathrm{P}_{\mathrm{Mu}}=0, \eta=0\right)$. The information on the level of power $\mathrm{P}_{\mathrm{Pc}_{\mathrm{c}}}$ absorbed then by the pump and entirely lost in the system is particularly important at the system operation with unloaded motor (when $\mathrm{M}_{\mathrm{M}}=0$ or $\mathrm{F}_{\mathrm{M}}=0$ ). Power $\mathrm{P}_{\mathrm{Pc}_{\mathrm{c}}}$ of the pump operating with hydraulic motor stopped (when $\omega_{\mathrm{M}}=0$ or $\mathrm{v}_{\mathrm{M}}=0$ ) may be minimized by simultaneous cutting of the pump discharge conduit from the hydraulic motor and connecting this conduit with the tank, i.e. unloading the pump. However, this is only possible in an individual system, when the pump feeds only one hydraulic motor.

\section{DIAGRAM OF POWER INCREASE IN A HYDRAULIC MOTOR}

Fig. 3.1 illustrates the diagram, proposed by the author, of power increase in a rotational hydraulic motor opposite to the direction of power flow, replacing the Sankey diagram of power decrease in the direction of power flow. 


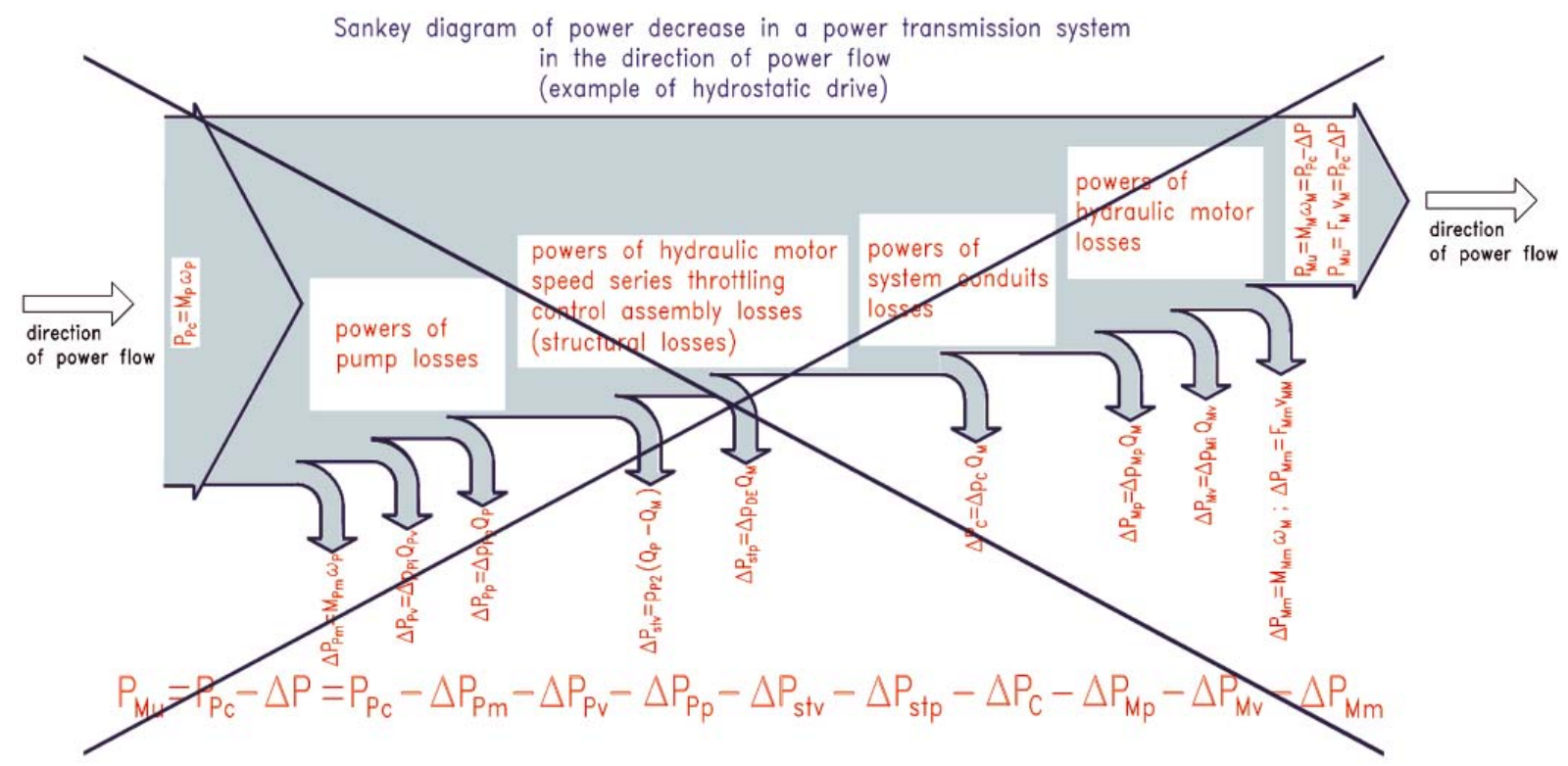

diagram, according to Z.Paszota, of power increase in a power transmission system opposite to the direction of power flow

(example of hydrostatic drive)
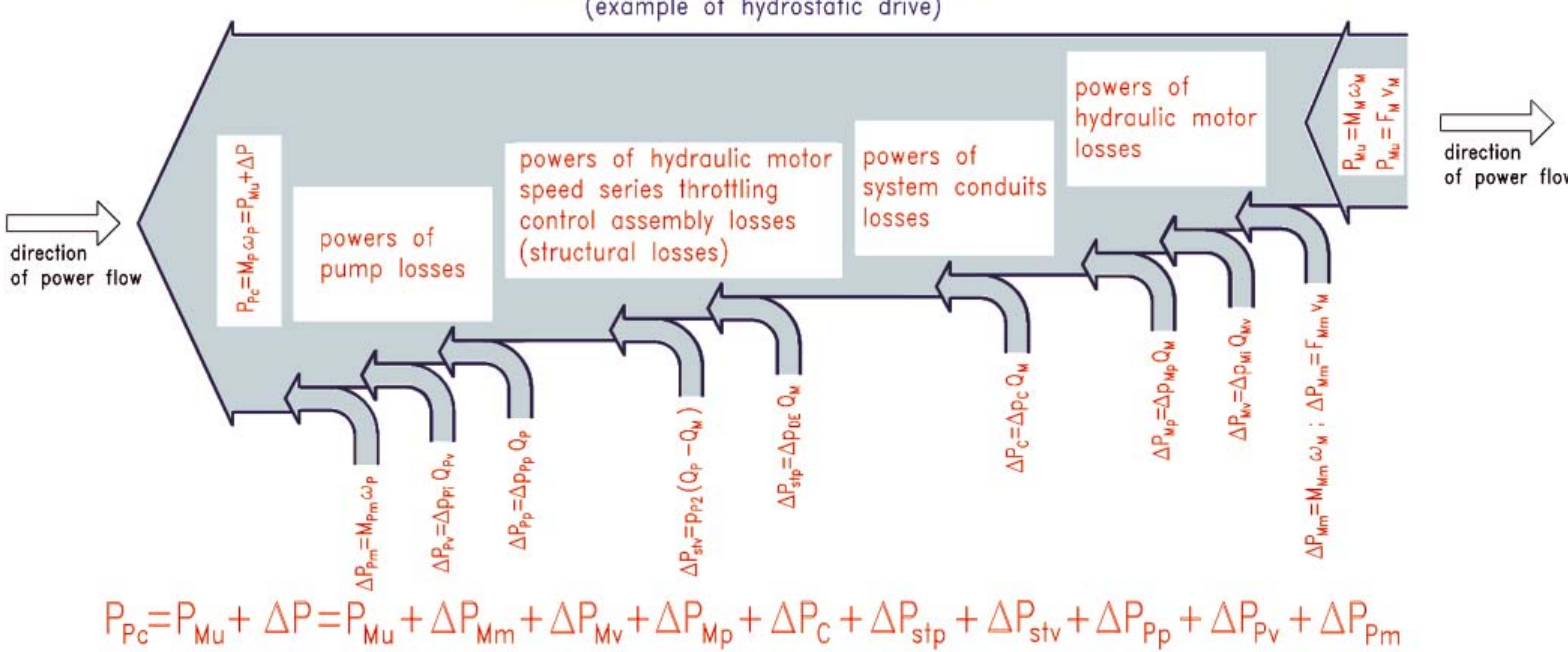

Fig. 2.1. Diagram, proposed by the author, of power increase in a hydrostatic drive system opposite to the direction of power flow, replacing the Sankey diagram of power decrease in the direction of power flow.

Power increases from the motor useful power $P_{M u}$, required by the driven machine (device) on the rotational motor shaft or on the linear motor piston rod, to the power $P_{P_{c}}$ consumed and required by the pump shaft from the motor (electric or internal combustion) driving the pump. The increase of power is a sum $\triangle P$ of powers of losses in the system elements (example of a system with the hydraulic motor speed series throttling control fed by a constant capacity pump cooperating with an overflow valve).

Powers of the losses are functions of the output parameters: $M_{M}$, $\omega_{M}$ of the rotational hydraulic motor shaft or $F_{M}$, $v_{M}$ of the linear hydraulic motor piston rod and diversified functions of the working fluid viscosity $v$.

$P_{M u}=M_{M} \omega_{M}$-motor useful power on the rotational motor shaft required by the driven machine (device); $P_{M u}=F_{M} v_{M}-$ motor useful power on the linear motor piston rod, $\Delta P_{M m}=M_{M m} \omega_{M}$-power of mechanical losses in the rotational motor, $\Delta P_{M m}=F_{M m} v_{M}-$ power of mechanical losses in the linear motor, $\Delta P_{M v}=\Delta p_{M i} Q_{M v}$ - power of volumetric losses in the motor, $\Delta P_{M p}=\Delta p_{M p} Q_{M}-$ power of pressure losses in the motor, $\Delta P_{C}=\Delta p_{C} Q_{M}-$ power of pressure losses in the system conduits, $\Delta P_{s p}=\Delta p_{D E} Q_{M}$-power of structural pressure losses in the throttling control assembly (in servo-valve, directional

proportional valve, set throttling valve or set two-way flow regulator), $\Delta P_{s t v}=p_{S P}\left(Q_{P}-Q_{M}\right)$ - power of structural volumetric losses in the throttling

control assembly (in the overflow valve), $\Delta P_{P p}=\Delta p_{P p} Q_{P}$ - power of pressure losses in the pump, $\Delta P_{P_{v}}=\Delta p_{P_{i}} Q_{P_{v}}-$ power of volumetric losses in the pump, $\Delta P_{P m}=M_{P m} \omega_{P}$-power of mechanical losses in the pump, $P_{P_{c}}=M_{P} \omega_{P}$-power consumed on the pump shaft, required by the pump shaft from the motor driving the pump

The power $\mathrm{P}_{\mathrm{Mc}}$ consumed by the hydraulic motor is a sum of motor shaft useful power $\mathrm{P}_{\mathrm{Mu}}$ and powers of three different energy losses in the motor. The losses occur in series (one after another), increasing the power in the opposite direction to the direction of power flow. In effect, the power in the motor increases from the shaft useful power $\mathrm{P}_{\mathrm{Mu}}$ to the working fluid power $\mathrm{P}_{\mathrm{Mc}}$ consumed by the motor:

$$
\mathrm{P}_{\mathrm{Mc}}=\mathrm{P}_{\mathrm{Mu}}+\Delta \mathrm{P}_{\mathrm{Mm}}+\Delta \mathrm{P}_{\mathrm{Mv}}+\Delta \mathrm{P}_{\mathrm{Mp}}
$$

Mechanical losses (and power $\Delta \mathrm{P}_{\mathrm{Mm}}$ of mechanical losses) occur in the ,shaft - working chambers” assembly.
Volumetric losses (and power $\Delta \mathrm{P}_{\mathrm{Mv}}$ of volumetric losses) occur in the working chambers.

Pressure losses (and power $\Delta \mathrm{P}_{\mathrm{Mp}}$ of pressure losses) occur in the motor channels.

\section{DIAGRAM OF POWER INCREASE IN A PUMP}

Fig. 4.1 presents the diagram, proposed by the author, of power increase in a pump opposite to the direction of power flow, replacing the Sankey diagram of power decrease in the direction of power flow. 

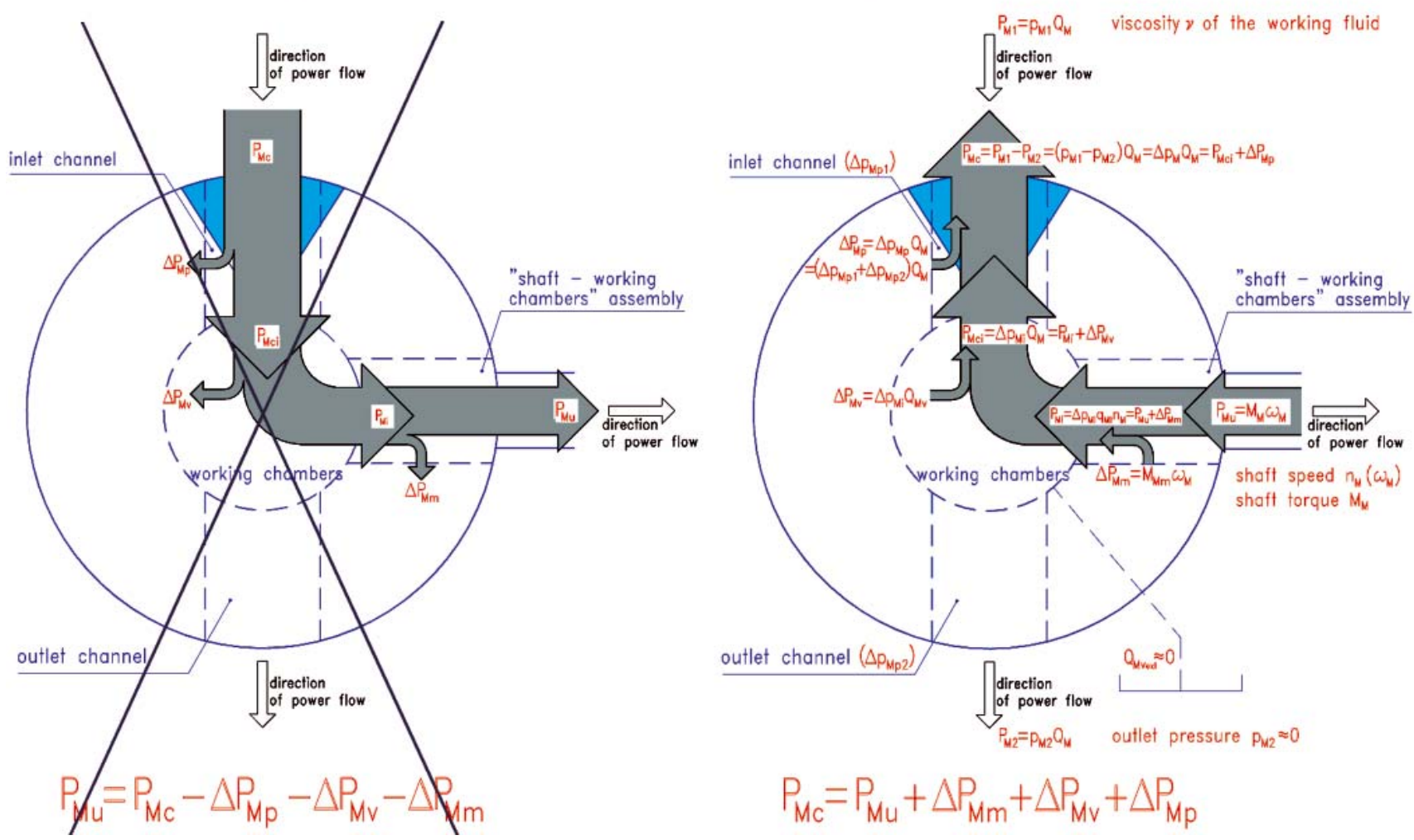

Fig. 3.1. Diagram of power increase in a rotational displacement hydraulic motor opposite to the direction of power flow, replacing the Sankey diagram of power decrease in the direction of power flow Power increases from the motor useful power $P_{\text {Mu }}$ required on the motor shaft by the driven machine (device) to power $P_{M c}$ consumed and required by the motor from the working fluid.

The increase of power is an effect of the powers of losses in the motor: power $\triangle P_{M m}$ of mechanical losses in the ,shaft- working chambers" assembly, power $\Delta P_{M_{v}}$ of volumetric losses in the working chambers and power $\Delta P_{M_{p}}$ of pressure losses in the motor channels.

Powers $\triangle P_{M m}, \Delta P_{M v}$ and $\triangle P_{M p}$ of the losses are functions of the output parameters of the motor assembly where the losses occur and diversified functions of the working fluid viscosity v: power $\Delta P_{M m}$ of mechanical losses is a function of torque $M_{M}$ and shaft speed $n_{M}\left(\Delta_{M}\right)$ required from the motor by the driven machine (device) and a function of the working fluid viscosity $\Delta$, power $\Delta P_{M v}$ of volumetric losses is a function of the decrease $\Delta p_{M i}$ of pressure indicated in working chambers (torque $M_{M i}$ indicated in the chambers) and of the shaft rotational speed $n_{M}$ as well as a function of the working fluid viscosity $v$, power $\Delta P_{M p}$ of pressure losses is a function of motor capacity $Q_{M}$ and of the working fluid viscosity $v$.

Power $P_{M i}$ indicated in the working chambers: $P_{M i}=P_{M u}+\Delta P_{M m}$, power $P_{M c i}$ of the working fluid consumed in the working chambers:

$P_{M c i}=P_{M u}+\Delta P_{M m}+\Delta P_{M v}$ power $P_{M c}$ of the working fluid consumed by the motor: $P_{M c}=P_{M u}+\Delta P_{M m}+\Delta P_{M v}+\Delta P_{M p}$.

The diagram replaces the Sankey diagram of distribution of power in a hydraulic motor causing incorrect loss evaluation during the hydraulic motor energy investigations

The power $\mathrm{P}_{\mathrm{Pc}}$ consumed by the pump shaft is a sum of pump useful power $\mathrm{P}_{\mathrm{Pu}}$ and powers of three different losses in the pump. The losses occur in series (one after another), increasing the power in the opposite direction to the direction of power flow. In effect, the power in the pump increases from the working fluid useful power $\mathrm{P}_{\mathrm{Pu}}$ to the pump shaft consumed power $\mathrm{P}_{\mathrm{Pc}}$ :

$$
\mathrm{P}_{\mathrm{Pc}}=\mathrm{P}_{\mathrm{Pu}}+\Delta \mathrm{P}_{\mathrm{Pp}}+\Delta \mathrm{P}_{\mathrm{Pv}}+\Delta \mathrm{P}_{\mathrm{Pm}}
$$

Pressure losses (and power $\Delta \mathrm{P}_{\mathrm{Pp}}$ of pressure losses) occur in the pump channels.

Volumetric losses (and power $\Delta \mathrm{P}_{\mathrm{Pv}_{\mathrm{v}}}$ of volumetric losses) occur in the working chambers.

Mechanical losses (and power $\Delta \mathrm{P}_{\mathrm{Pm}}$ of mechanical losses) occur in the ,working chambers - shaft” assembly.

\section{MATHEMATICAL MODELS OF THE DISPLACEMENT MACHINE LOSSES}

Assessment of the capability of energy savings in the hydrostatic drive system operation requires the system losses to be defined.

The simulation determination of the system energy efficiency may be used for the purpose in the system design and operation process [24]. The following factors in the simulation model should be taken into account:
- the hydraulic motor speed control system structure,

- energy losses in the system elements,

- the pump driving motor speed decrease,

- the system control element characteristics,

- load and speed of the controlled hydraulic motor,

- hydraulic oil viscosity, changing in the system operation process due to change of the oil temperature.

In order to make the transmission system efficiency determination method easily applicable, it is necessary to:

1) use the computer programs for the mathematical models, allowing to analyse the hydraulic system efficiency as a function of the decisive parameters (hydraulic motor speed coefficient $\bar{\omega}_{M}$ and load coefficient $\overline{\mathrm{M}}_{\mathrm{M}}$, ratio $v / v_{\mathrm{n}}$ of the hydraulic oil viscosity $v$ to the reference viscosity $v_{n}$ ),

2) determine the values of energy loss coefficients $k_{i}$ for the pump, rotational hydraulic motor or hydraulic cylinder. Those coefficients should be clearly defined and precisely determined for a given displacement machine.

The mathematical model of the displacement machine losses allowing to fulfil the conditions given in points 1 and 2 above should take into account:

a) the form and simplicity of the description, deciding of the possible use of that description in the system efficiency model, with maintaining the system efficiency precise assessment, 

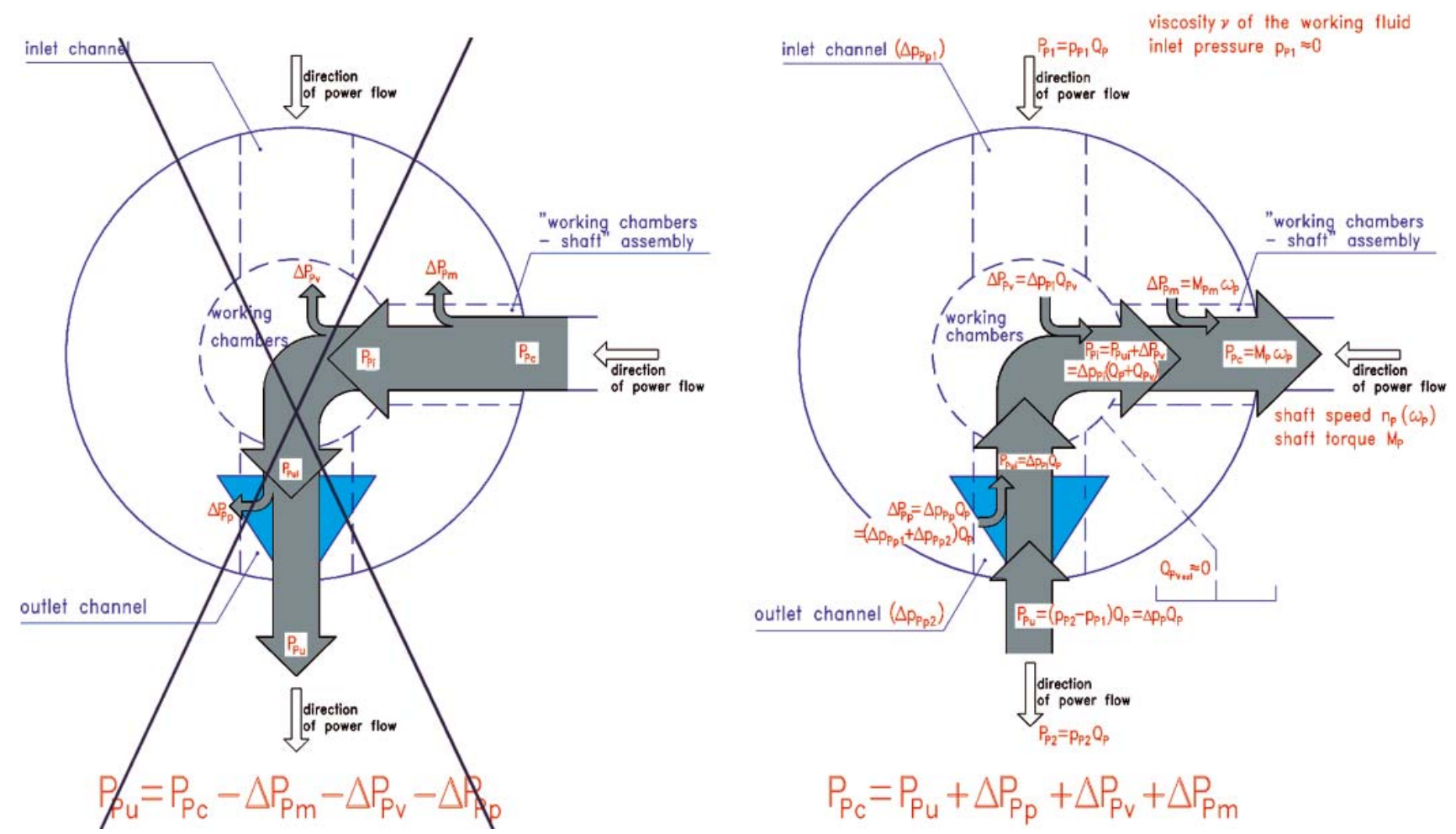

Fig. 4.1. Diagram of power increase in a displacement pump opposite to the direction of power flow replacing the Sankey diagram of power decrease in the direction of power flow Power increases from the motor useful power $P_{P_{u}}$, required by the working fluid in the discharge conduit of the pump, to power $P_{P_{c}}$ consumed and required by the pump shaft from (electric or internal combustion) motor driving the pump.

The increase of power is an effect of the powers of losses in the pump: power $\Delta P_{P p}$ of pressure losses in the pump channels, power $\Delta p_{P v}$ of volumetric losses in the working chambers and power $\Delta P_{P m}$ of mechanical losses in the ,working chambers - shaft" assembly.

Powers $\Delta P_{P_{p}}, \Delta P_{P_{v}}$ and $\Delta P_{P_{m}}$ of the losses are functions of the output parameters of the pump assembly where the losses occur and diversified functions of the working fluid viscosity $v$ : power $\Delta P_{P p}$ of pressure losses is a function of pump capacity $Q_{P}$ and of the working fluid viscosity $v$, power $\Delta P_{P v}$ of volumetric losses is a function of the increase $\Delta p_{P i}$ of pressure indicated in working chambers and of the shaft rotational speed $n_{P}$ as well as a function of the working fluid viscosity $v$, power $\Delta P_{P m}$ of mechanical losses is a function of the torque $M_{P i}$ indicated in the chambers, of the pump shaft speed $n_{P}\left(\omega_{P}\right)$ and a function of the working fluid viscosity $v$.

Useful power $P_{P u i}$ of the working fluid in the working chambers: $P_{P u i}=P_{P u}+\Delta P_{P p}$, power $P_{P i}$ indicated in the working chambers: $P_{P i}=P_{P_{u}}+\Delta P_{P p}+\Delta P_{P v}$ power $P_{P_{c}}$ consumed on the pump shaft: $P_{P_{c}}=P_{P u}+\Delta P_{P p}+\Delta P_{P v}+\Delta P_{P m}$.

The diagram replaces the Sankey diagram of distribution of power in a pump, causing incorrect loss evaluation during the pump energy investigations

b) description of the displacement machine mechanical, volumetric and pressure losses, allowing to evaluate the impact of hydraulic oil kinematic viscosity changing with oil temperature,

c) separate treatment of the mechanical, volumetric and pressure losses in the machine.

It is necessary to perform the laboratory and simulation investigations in the displacement machine real operating conditions. The investigations should allow to verify the proposed models of:

- machine mechanical losses,

- machine volumetric losses,

- machine pressure losses,

in the full range of working pressure up to nominal pressure $\mathrm{p}_{\mathrm{n}}$, in the wide range of pump capacity up to theoretical capacity $\mathrm{Q}_{\mathrm{Pt}}$ and in wide range of the hydraulic oil kinematic viscosity $v$, and also to determine the $\mathbf{k}_{\mathrm{i}}$ coefficients of specific losses.

\section{MODEL OF VOLUMETRIC LOSSES IN THE PUMP WORKING CHAMBERS}

Volumetric losses in the pump are connected first of all with the working liquid leaks through slots between displacement elements and the working chamber walls, distributor (if it exists) elements and are also effect of the liquid compressibility, change of the pump working chambers volume and change of the slot height due to changes of pressure and temperature.

The model of volumetric losses presented in [24, 25 and $26]$ meets the requirements given in chapter 5. The author assumes the conditions and simplifications of the impact of certain factors on those losses and that impact is reflected in the coefficient $\mathrm{k}_{1}$ of volumetric losses in the pump (equation (6.3)) and in power exponents describing the dependence of volumetric losses on $\Delta \mathrm{p}_{\mathrm{Pi}}$ and $v$ (equation (6.4)).

The theoretical working volume $q_{P t}\left(V_{P}\right)$ of constant or variable capacity pump (theoretical capacity $\mathrm{q}_{\mathrm{Pt}}$ for one pump shaft revolution - at the pump capacity coefficient $b_{\mathrm{P}}=1$ ) - the geometrical difference between the maximum and minimum volume of working chambers - is a characteristic value of a pump. It is determined at the pressure value $\mathbf{p}_{\mathrm{P} 1 \mathrm{i}}=\mathbf{0}$ in the pump working chambers during their filling and at the increase $\Delta \mathbf{p}_{\mathrm{Pi}}=\mathbf{0}$ of the indicated pressure in the working chambers.

Under the pressure and temperature, the geometric working volume $\mathrm{q}_{\mathrm{Pg}}$ of the pump changes slightly compared with $\mathrm{q}_{\mathrm{Pt}}$. It is assumed (in order to simplify the description of volumetric and mechanical losses in the pump) that the theoretical pump working volume $q_{\mathrm{Pt}}$ is constant and equal to the geometrical working volume $q_{P g}$ determined at the working liquid 
temperature corresponding to the recommended kinematic viscosity $v_{n}=35 \mathrm{~mm}^{2} \mathrm{~s}^{-1}$ :

$$
\mathrm{q}_{\mathrm{Pt}}=\mathrm{q}_{\mathrm{Pg}} \mid \begin{aligned}
& \mathrm{p}_{\mathrm{P} 1 \mathrm{i}}=0 \\
& \Delta \mathrm{p}_{\mathrm{Pi}}=0 \\
& v_{\mathrm{n}}
\end{aligned}
$$

and the change of geometric working volume $q_{\mathrm{Pg}}$ during the system operation will be taken into account in the values of loss coefficients $k_{i}$ in the pump.

The theoretical capacity $\mathrm{Q}_{\mathrm{Pt}}$ of a constant capacity pump is given by the formula:

$$
\mathrm{Q}_{\mathrm{Pt}}=\mathrm{q}_{\mathrm{Pt}} \mathrm{n}_{\mathrm{P} 0}
$$

where:

$\mathrm{n}_{\mathrm{P} 0}-$ the rotational shaft speed of an unloaded pump $\left(\Delta \mathrm{p}_{\mathrm{Pi}}=0\right)$.

Coefficient $\mathbf{k}_{1}$ of the volumetric losses $\mathbf{Q}_{\mathbf{P}_{\mathbf{y}}}$, determined during one shaft revolution of a constant or variable capacity pump, at the pressure increase $\Delta \mathrm{p}_{\mathrm{Pi}}$ equal to the hydraulic system nominal pressure $\Delta \mathrm{p}_{\mathrm{Pi}}=\mathrm{p}_{\mathrm{n}}$ and at the viscosity $v_{\mathrm{n}}$, the losses related to the pump theoretical working volume $\mathrm{q}_{\mathrm{Pt}}\left(\mathrm{V}_{\mathrm{P}}\right)$, is described by the formula:

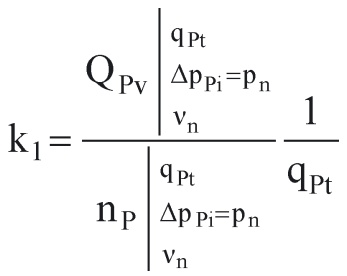

Using the volumetric loss coefficient $\mathrm{k}_{1}$ the following mathematical model for the intensity $\mathrm{Q}_{\mathrm{P}_{\mathrm{v}}}$ of volumetric losses in the pump is proposed:

$$
\mathrm{Q}_{\mathrm{Pv}}=\left.\mathrm{k}_{1} \mathrm{q}_{\mathrm{Pt}} \mathrm{n}_{\mathrm{P}}\right|_{\substack{\mathrm{p}_{\mathrm{Pi}} \\ \mathrm{v}_{\mathrm{n}}}} ^{\mathrm{q}_{\mathrm{n}}}\left(\frac{\Delta \mathrm{p}_{\mathrm{Pi}}}{\mathrm{p}_{\mathrm{n}}}\right)^{1}\left(\frac{v}{v_{\mathrm{n}}}\right)^{-0.8}
$$

The use of coefficient $\mathrm{k}_{1}$ of volumetric losses for description of the relation of intensity $\mathrm{Q}_{\mathrm{Pv}}$ to the indicated increase $\Delta \mathrm{p}_{\mathrm{Pi}}$ of pressure in the pump working chambers allows to describe that relation by an exponential function with the exponent not necessarily equal to 1 .

The expression describing the variable capacity pump capacity takes the form:

$\mathrm{Q}_{\mathrm{P}}=\mathrm{b}_{\mathrm{P}} \mathrm{q}_{\mathrm{Pt}} \mathrm{n}_{\mathrm{P}}-\mathrm{k}_{1} \mathrm{q}_{\mathrm{Pt}} \mathrm{n}_{\mathrm{P}} \mid \begin{aligned} & \mathrm{q}_{\mathrm{Pt}} \\ & \begin{array}{l}\Delta \mathrm{p}_{\mathrm{Pi}}=\mathrm{p}_{\mathrm{n}} \\ v_{\mathrm{n}}\end{array}\end{aligned}\left(\frac{\Delta \mathrm{p}_{\mathrm{Pi}}}{\mathrm{p}_{\mathrm{n}}}\right)^{1}\left(\frac{v}{v_{\mathrm{n}}}\right)^{-0.8}$

The expressions (6.4) and (6.5) assume, that change of the capacity coefficient $b_{\mathrm{P}}$ in the variable capacity pump (change of the pump capacity) does not influence the intensity of pump volumetric losses $\mathbf{Q}_{\mathrm{Pv}}$

In expressions (6.4) and (6.5), the value 1 of exponent describing the impact of the $\Delta \mathrm{p}_{\mathrm{Pi}} / \mathrm{p}_{\mathrm{n}}$ ratio and also the value -0.8 of exponent describing the impact of the $v / v_{n}$ ratio on the intensity $\mathrm{Q}_{\mathrm{Pv}}$ of pump volumetric losses should take into account all the factors influencing the volumetric losses (character of the flow in slots, change of the slots cross-section with pressure and temperature, liquid compressibility, change of the liquid viscosity in slots etc.).

The value 1 of exponent describing the impact of the $\Delta \mathbf{p}_{\mathrm{Pi}} / \mathbf{p}_{\mathrm{n}}$ ratio and also the value $\mathbf{- 0 . 8}$ of exponent describing the impact of the $v / v_{n}$ ratio on the intensity $Q_{P v}$ of pump volumetric losses must be verified experimentally for each pump type.
Compressibility of the working liquid has an essential effect on the evaluation of the intensity $\mathrm{Q}_{\mathrm{P}_{\mathrm{v}}}$ of volumetric losses in the pump (equation (6.4)) and on the evaluation of coefficient $\mathrm{k}_{1}$ of volumetric losses in the pump (equation (6.5)). The greater the liquid compressibility (mainly due to its aeration with the air not dissolved in the liquid) the greater the value of coefficient $\mathrm{k}_{1}$ determined in the pump investigation. Therefore, the liquid compressibility effects the evaluation of tightness of the pump structural solution. It may be particularly evident in the displacement pump operating at high values $(32 \div 40 \mathrm{MPa})$ of indicated pressure increase $\Delta \mathrm{p}_{\mathrm{Pi}}$ in the pump working chambers.

\section{VERIFICATION OF THE MATHEMATICAL MODEL OF VOLUMETRIC LOSSES IN THE PUMP WORKING CHAMBERS}

Laboratory investigations of an axial piston variable displacement pump of bent axis design (HYDROMATIK A7V.58.DR.1.R.P.F.00 type - Fig. 7.1) were carried out by Jan Koralewski [20, 22] on a test stand (Fig. 7.2) in the Chair of Hydraulics and Pneumatics of the Gdansk University of Technology, Mechanical Engineering Faculty.

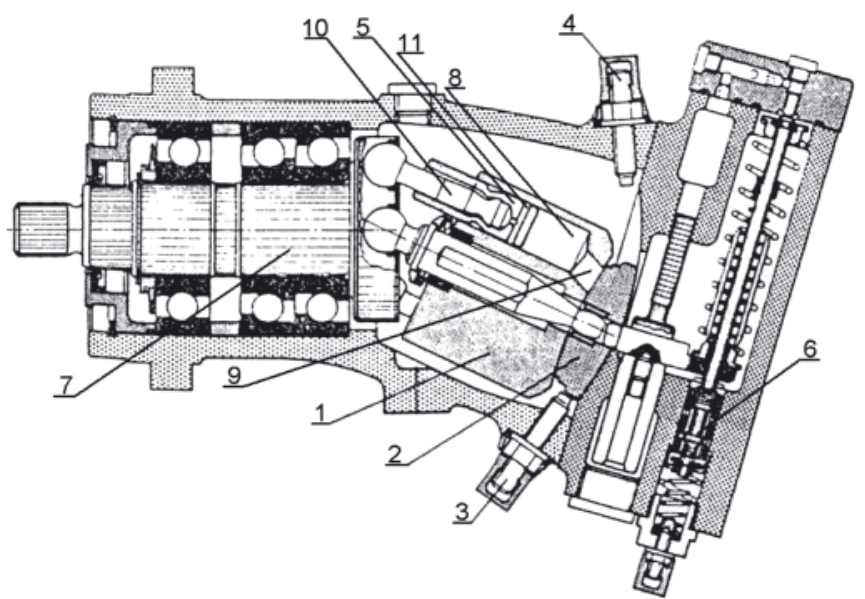

Fig. 7.1. Axial piston variable displacement pump of bent axis design (HYDROMATIK 7V.58.DR.1.R.P.F.00 type) [23]. 1) cylinder block, 2) collector (distributor), 3, 4) blockage of pump setting, 5) piston, 6) assembly of capacity zeroing at maximum set pressure, 7) shaft, 8) working chamber, 9) hole in the cylinder block connecting working chamber (8) with collector (distributor) (2), 10) connector with ball-andsocket joints-element of the ,, working chamber-shaft" assembly, 11) circumferential groove in the piston

In order to verify the mathematical model described by formula (6.4), it was replaced by a mathematical expression taking into account the relations, obtained during the investigations, of the intensity $\mathrm{Q}_{\mathrm{P}_{\mathrm{v}}}$ of pump volumetric losses to the indicated increase $\Delta \mathrm{p}_{\mathrm{Pi}}$ of pressure in the pump working chambers (to the $\Delta \mathrm{p}_{\mathrm{Pi}} / \mathrm{p}_{\mathrm{n}}$ ratio) and also to the oil viscosity ratio $v / v_{\mathrm{n}}[20,22]$ :

$$
\mathrm{Q}_{\mathrm{Pv}}=\left.\mathrm{k}_{1} \mathrm{q}_{\mathrm{Pt}} \mathrm{n}_{\mathrm{P}}\right|_{\Delta \mathrm{p}_{\mathrm{Pi}}=\mathrm{p}_{\mathrm{n}}} ^{\mathrm{q}_{\mathrm{Pt}}}\left(\frac{\Delta \mathrm{p}_{\mathrm{Pi}}}{\mathrm{p}_{\mathrm{n}}}\right)^{\mathrm{a}_{\mathrm{pv}}}\left(\frac{v}{v_{\mathrm{n}}}\right)^{\mathrm{a}_{\mathrm{vv}}}
$$

The obtained values (Fig. 7.3) of the coefficient $\mathbf{k}_{\mathbf{1}}=\mathbf{0 . 0 6 5}$ of intensity $\mathrm{Q}_{\mathrm{Pv}}$ of volumetric losses, exponent $\mathrm{a}_{\mathrm{pv}}=0.97$ of the relation of intensity $\mathrm{Q}_{\mathrm{Pv}_{\mathrm{v}}}$ of the volumetric losses to the ratio $\Delta \mathrm{p}_{\mathrm{Pi}} / \mathrm{p}_{\mathrm{n}}$ of the pressure increase in the working chambers, exponent $\mathrm{a}_{\mathrm{vV}}=-0.30$ of the relation of intensity $\mathrm{Q}_{\mathrm{Pv}}$ of the volumetric losses to the $v / v_{n}$ ratio of oil viscosity, have made it possible to present the mathematical model of the intensity $\mathrm{Q}_{\mathrm{Pv}_{\mathrm{v}}}$ of pump volumetric losses in the form: 


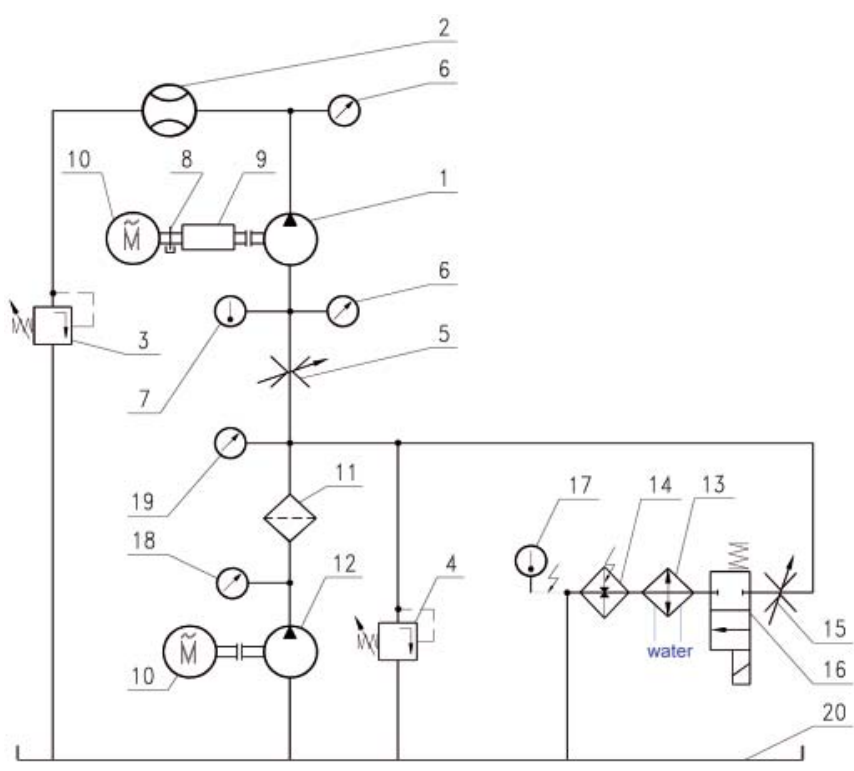

Fig. 7.2. Test stand for investigating of the volumetric and mechanical losses in the pump (HYDROMATIK A7V.58.DR.1.R.P.F.00 type) [23].

1) investigated pump, 2) piston flow-meter, 3,4) overflow valve,

5,15) throttling valve, 6) pressure sensor, 7) temperature sensor, 8) rotational speed sensor, 9) torque sensor, 10) asynchronic motor,

11) filter, 12) feeding screw pump, 13) cooler, 14) electric heater, 16) distributor, 17) thermostat, 18) manometer, 19) vacuum meter, 20) tank

$$
\mathrm{Q}_{\mathrm{Pv}}=\left.0.065 \mathrm{q}_{\mathrm{Pt}} \mathrm{n}_{\mathrm{P}}\right|_{\Delta \mathrm{p}_{\mathrm{Pi}}=\mathrm{p}_{\mathrm{n}}} ^{\mathrm{q}_{\mathrm{Pt}}}\left(\frac{\Delta \mathrm{p}_{\mathrm{Pi}}}{\mathrm{p}_{\mathrm{n}}}\right)^{0.97}\left(\frac{\mathrm{v}}{\mathrm{v}_{\mathrm{n}}}\right)^{-0.30}
$$

Model (7.2) describes precisely the intensity $\mathrm{Q}_{\mathrm{P}_{\mathrm{v}}}$ of volumetric losses in the nominal conditions of the pump operation, i.e. at the pump capacity coefficient $b_{P}=1$, the pressure increase ratio $\Delta \mathrm{p}_{\mathrm{Pi}} / \mathrm{p}_{\mathrm{n}}=1\left(\mathrm{p}_{\mathrm{n}}=32 \mathrm{MPa}\right)$ and the oil viscosity ratio $v / v_{\mathrm{n}}=1\left(v_{\mathrm{n}}=35 \mathrm{~mm}^{2} \mathrm{~s}^{-1}\right)$. At the same time, this mathematical model is a simulation formula describing the change of intensity $\mathrm{Q}_{\mathrm{Pv}_{\mathrm{v}}}$ of volumetric losses with the change of the pressure increase ratio $\Delta \mathrm{p}_{\mathrm{pi}} / \mathrm{p}_{\mathrm{n}}$ and the oil viscosity ratio $v / v_{\mathrm{n}}$ (the change of pump capacity coefficient $b_{\mathrm{P}}$ has practically no impact on the change of intensity $\mathrm{Q}_{\mathrm{P}_{\mathrm{v}}}$ of volumetric losses).

However, the value of coefficient $\mathbf{k}_{\mathbf{1}}=\mathbf{0 . 0 6 5}$ (equations (6.3), (7.1), (7.2)) of the intensity $\mathrm{Q}_{\mathrm{Pv}}$ of volumetric losses, determined during one shaft revolution of the pump, at the pressure increase $\Delta \mathrm{p}_{\mathrm{Pi}}$ equal to the system nominal pressure $\mathrm{p}_{\mathrm{n}}$ $-\Delta \mathrm{p}_{\mathrm{Pi}}=\mathrm{p}_{\mathrm{n}}$ and at the viscosity $\mathrm{v}_{\mathrm{n}}$ (the losses related to the pump theoretical working volume $\mathrm{q}_{\mathrm{Pt}}$ ) is influenced by the working liquid compressibility coefficient $\mathbf{k}_{\mathrm{lc}}$.

The liquid compressibility coefficient $\mathrm{k}_{\mathrm{lc}}$ increases the value of coefficient $\mathrm{k}_{1}$ of volumetric losses in the pump, „loading” the pump structure with non-existent excessive leakage mainly from the working chambers under the high discharge channel pressure to the working chambers connected with the low pressure inlet channel.

In the conditions of aerated hydraulic oil and high working pressure in the pump discharge channel, the value of liquid compressibility coefficient $\mathbf{k}_{\mathrm{lc}}$ can significantly increase the value of volumetric loss coefficient $k_{1}$ and at the same time significantly decrease the value of coefficient $\mathbf{k}_{4.2}$ of the increase $\Delta M_{\mathrm{Pm} \mid \Delta \mathrm{p}_{\mathrm{Pi}}}, b_{\mathrm{p}}, v_{\mathrm{n}}$ of the torque of mechanical losses in the pump.

Part II of the paper (titled: „Effect of the working liquid compressibility on the picture of volumetric losses in a high pressure displacement pump used in a hydrostatic drive, Part II

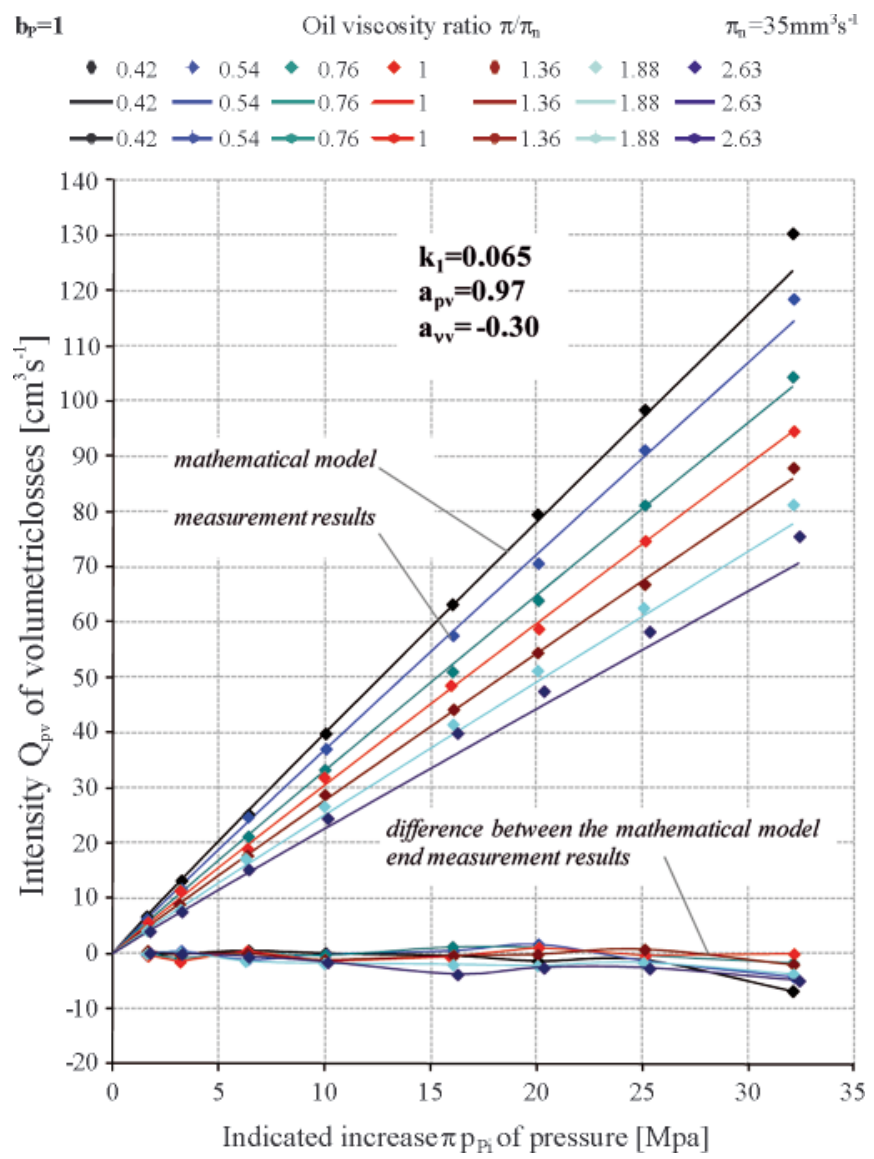

Fig. 7.3. Comparison of the intensity $Q_{P v}$ of volumetric losses described by the mathematical model (6) with the laboratory investigation results and the absolute difference between the mathematical model values and the laboratory investigation values; assumed were: the coefficient $k_{I}=0.065$ of volumetric losses, exponent $a_{p v}=0.97$, exponent $a_{v v}=-0,30$; example for the pump capacity coefficient $b_{P}=1$ (pump HYDROMATIK A7V.58. DR.1.R.P.F.00 type) [20, 22$]$

- Mechanical losses in a pump) to be published in the next issue of this journal will present a possibility of determining a value of the $\mathrm{k}_{\mathrm{lc} \mid \mathrm{p}_{\mathrm{n}}}$ coefficient and its effect on the $\mathrm{k}_{4.2}$ and $\mathrm{k}_{1}$ coefficient.

\section{BIBLIOGRAPHY}

1. Paszota Z.: Graphical presentation of the power of energy losses and power developed in the elements of hydrostatic drive and control system. Part I-Rotational hydraulic motor speed series throttling control systems. Chapter in the monograph: ,, Research, design, production and operation of hydraulic systems" (in Polish), Adam Klich, Edward Palczak and Andrzej Meder editors. „Cylinder” Library. Komag Mining Mechanisation Centre, Gliwice 2008

2. Paszota Z.: Graphical presentation of the power of energy losses and power developed in the elements of hydrostatic drive and control system. Part II - Rotational hydraulic motor speed parallel throttling control and volumetric control systems. Chapter in the monograph: ,, Research, design, production and operation of hydraulic systems" (in Polish), Adam Klich, Edward Palczak and Andrzej Meder editors. „Cylinder” Library. Komag Mining Mechanisation Centre, Gliwice 2008

3. Paszota Z:: Direction of increase of power stream in the hydrostatic drive and control system. Graphical presentation of the power of energy losses and power developed in the elements of hydrostatic drive and control system. Part I - Rotational hydraulic motor speed series throttling control systems (in Polish), Napędy i sterowanie, scientific monthly, No 10 (114), October 2008

4. Paszota Z:: Direction of increase of power stream in the hydrostatic drive and control system. Graphical presentation of 
the power of energy losses and power developed in the elements of hydrostatic drive and control system. Part II - Rotational hydraulic motor speed parallel throttling control and volumetric control systems (in Polish), Napędy i sterowanie, scientific monthly, No 11 (115), November 2008

5. Paszota Z.: Graphical presentation of the power of energy losses and power developed in the elements of hydrostatic drive and control system. Part I - Rotational hydraulic motor speed series throttling control systems. Polish Maritime Research 3 (57) 2008, Vol. 15

6. Paszota Z.: Graphical presentation of the power of energy losses and power developed in the elements of hydrostatic drive and control system. Part II - Rotational hydraulic motor speed parallel throttling control and volumetric control systems. Polish Maritime Research 4 (58) 2008,Vol. 15

7. Paszota Z.: The operating field of a hydrostatic drive system. Chapter in the monograph: ,Research, design, production and operation of hydraulic systems" (in Polish), Adam Klich, Antoni Kozieł and Edward Palczak editors. „Cylinder” Library. Komag Mining Mechanisation Centre, Gliwice 2009

8. Paszota Z.: Parameters of the energy efficiency investigations of pumps and hydraulic motors. The operating field of a hydrostatic drive system (in Polish), Napędy i sterowanie, scientific monthly, No 11 (127), November 2009

9. Paszota Z.: The operating field of a hydrostatic drive system parameters of the energy efficiency investigations of pumps and hydraulic motors. Polish Maritime Research 4 (62) 2009, Vol. 16

10.Paszota Z.: Energy losses in a rotational hydraulic motordefinitions and relations for evaluation of the efficiency of motor and hydrostatic drive. Chapter in the monograph: ,,Research, design, production and operation of hydraulic systems" (in Polish), Adam Klich, Antoni Kozieł and Edward Palczak editors. „Cylinder” Library. Komag Mining Mechanisation Centre, Gliwice 2010

11.Paszota Z.: Theoretical and mathematical models of the torque of mechanical losses in a hydraulic rotational motor for hydrostatic drive. Chapter in the monograph: ,, Research, design, production and operation of hydraulic systems" (in Polish), Adam Klich, Antoni Kozieł and Edward Palczak editors. „Cylinder” Library. Komag Mining Mechanisation Centre, Gliwice 2010

12.Paszota Z.: Energy losses in a rotational hydraulic motor definitions and relations for evaluation of the efficiency of motor and hydrostatic drive (in Polish), Napędy i sterowanie, scientific monthly, No 10 (138), October 2010

13.Paszota Z.: Theoretical and mathematical models of the torque of mechanical losses in a hydraulic rotational motor for hydrostatic drive (in Polish), Napędy i sterowanie, scientific monthly, No 11(139), November 2010

14.Paszota Z.: Energy losses in the hydraulic rotational motordefinitions and relations for evaluation of the efficiency of motor and hydrostatic drive. Polish Maritime Research $2 / 2010$

15.Paszota Z.: Theoretical and mathematical models of the torque of mechanical losses in a hydraulic rotational motor for hydrostatic drive. Polish Maritime Research 3/2010
16.Paszota Z.: Hydrostatic drives as safe and energy saving machines (in Polish), Napędy i sterowanie, scientific monthly, No 1(141), January 2011

17.Paszota Z.: Hydrostatic drives as safe and energy saving machines (in Polish), Proceedings of the ,Innovative machines and Technologies - Safety" conference, Szczyrk 03 - 04 February 2011

18.Paszota Z.: Hydrostatic drives as safe and energy saving machines. The drive investigation method compatible with the diagram of power increase opposite to the direction of power flow. Polish Maritime Research 1/2011,

19.Paszota Z.: Theoretical models of the torque of mechanical losses in the pump used in a hydrostatic drive. Polish Maritime Research 4 / 2011,

20.Koralewski J.: Influence of hydraulic oil viscosity on the volumetric losses in a variable capacity pump. Polish Maritime Research. 3/2011

21.Czyński M.: Laboratory investigation of the model of hydrostatic transmission energy efficiency. (in Polish). Doctor dissertation. Szczecin University of Technology, Faculty of Marine Engineering, 2005,

22.Koralewski J.: Effect of the working liquid viscosity on the energy losses in a variable capacity piston pump. (in Polish). Doctor dissertation (continued). Gdansk University of Technology, Faculty of Ocean Engineering and Ship Technology,

23. Skorek G.: Energy characteristics of the hydraulic system with proportional control of the hydraulic cylinder fed by a constant capacity pump in a constant pressure and variable pressure system. (in Polish). Doctor dissertation. Gdansk University of Technology, Faculty of Ocean Engineering and Ship Technology, 2008

24.Paszota Z.: Model of volumetric losses in the variable capacity displacement pump used in hydrostatic drive (in Polish). „Napędy i Sterowania'2006”. „TECHNICON'06” Gdańsk, 25.10.2006.

25.Paszota Z.: Aspects énergétiques des transmissions hydrostatiques. Monograph, Gdansk 2002.

26.Paszota Z.: Model of the energy losses in the displacement rotational machines for description of efficiency of the hydrostatic drive. Part I. Model of volumetric losses. Polish Maritime Research. 3/2000.

\section{CONTACT WITH THE AUTHOR}

Prof. Zygmunt Paszota Faculty of Ocean Engineering and Ship Technology

Gdansk University of Technology Narutowicza 11/12

80-233 Gdansk, POLAND

e-mail: zpaszota@pg.gda.pl 